\title{
Investigation and management of iron deficiency anaemia in
}

\section{a specialist palliative care setting and the role of intravenous}

\section{iron: a descriptive analysis of hospice data [version 1; peer}

\section{review: 1 approved, 1 approved with reservations]}

\author{
Thomas Steele (iD)1, Helen Bonwick¹, Amara Callistus Nwosu (Did-3, Laura Chapman¹ \\ ${ }^{1}$ Marie Curie Hospice, Liverpool, Merseyside, L25 8QA, UK \\ 2International Observatory on End of Life Care, Lancaster University, Lancaster, Lancashire, LA1 4YG, UK \\ ${ }^{3}$ Academic Palliative and End of Life Care Centre, Liverpool University Hospitals NHS Foundation Trust, Liverpool, Merseyside, L7 \\ 8XP, UK
}

V1 First published: 28 Jan 2021, 3:6

https://doi.org/10.12688/amrcopenres.12963.1

Latest published: 22 Mar 2021, 3:6

https://doi.org/10.12688/amrcopenres.12963.2

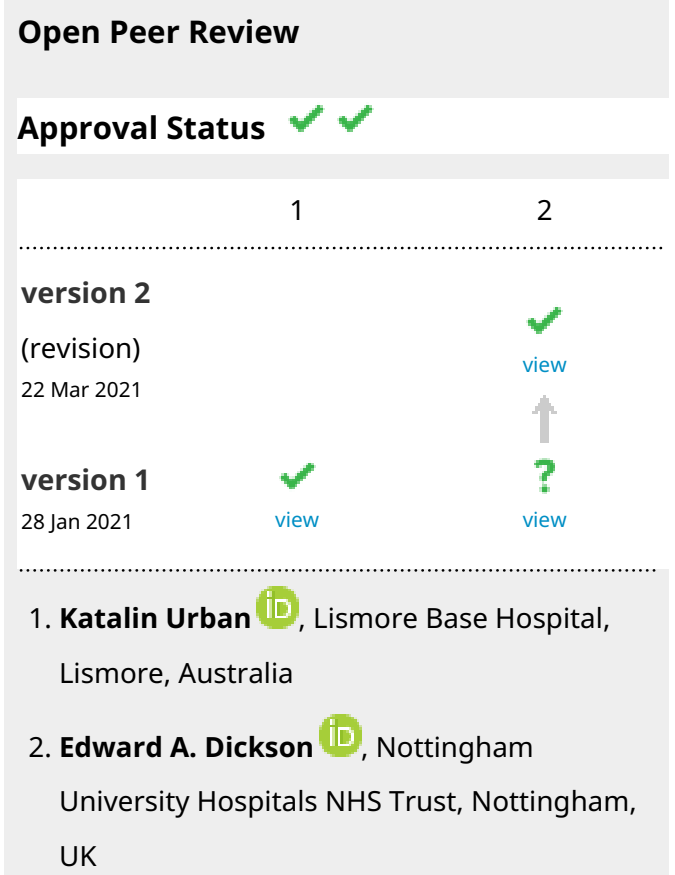

Any reports and responses or comments on the article can be found at the end of the article. 
in a hospice setting. Further research should define the optimum use of this approach in palliative care patients.

\section{Keywords}

Anaemia, iron deficiency, intravenous iron, hospice, palliative care

Corresponding author: Thomas Steele (tom.steele2@nhs.net)

Author roles: Steele T: Conceptualization, Data Curation, Formal Analysis, Investigation, Methodology, Project Administration, Visualization, Writing - Original Draft Preparation, Writing - Review \& Editing; Bonwick H: Conceptualization, Supervision, Writing Review \& Editing; Nwosu AC: Methodology, Supervision, Writing - Review \& Editing; Chapman L: Conceptualization, Supervision, Writing - Review \& Editing

Competing interests: No competing interests were disclosed.

Grant information: This research did not receive any specific grant from funding agencies in the public, commercial or not-for-profit sectors. The roles of all of the authors are supported by Marie Curie.

The funders had no role in study design, data collection and analysis, decision to publish, or preparation of the manuscript.

Copyright: $\odot 2021$ Steele T et al. This is an open access article distributed under the terms of the Creative Commons Attribution License, which permits unrestricted use, distribution, and reproduction in any medium, provided the original work is properly cited.

How to cite this article: Steele T, Bonwick $\mathrm{H}$, Nwosu AC and Chapman L. Investigation and management of iron deficiency anaemia in a specialist palliative care setting and the role of intravenous iron: a descriptive analysis of hospice data [version 1; peer review: 1 approved, 1 approved with reservations] AMRC Open Research 2021, 3:6 https://doi.org/10.12688/amrcopenres.12963.1

First published: 28 Jan 2021, 3:6 https://doi.org/10.12688/amrcopenres.12963.1 


\section{Plain language summary}

Many patients supported by hospices have anaemia. This can lead to symptoms including tiredness and shortness of breath. In severe cases, patients may be given a blood transfusion, however this carries significant risks and blood is a limited resource. Anaemia can be caused by a lack of iron. Iron deficiency can be treated with iron tablets or injections. However, iron tablets can have a lot of side effects and patients generally have to go to hospital for iron injections. There is little information into how important this is for anaemia that we see in hospices and how it should be treated.

We looked at the results of tests for iron deficiency done at a UK hospice in day-to-day practice. The hospice started doing these tests for appropriate patients with anaemia after it was recommended in recent guidelines. Out of the tests performed, a quarter showed iron deficiency. There were a higher number of patients with typical symptoms of anaemia and patients with a cancer of the gut in the group with iron deficiency. We also looked at treatment given for iron deficiency. Twelve were given iron injections at the hospice, which hasn't been reported before. This study was not designed to investigate how well this worked but there were no major side effects. It also seemed to improve blood counts and help symptoms in most.

Overall, this study showed that we were able to test for iron deficiency at the hospice, we found it often and, in certain patients, were able to treat it with iron injections at the hospice. Research in the future should look at how we could best use this approach. It should also look at the effectiveness of iron injections in hospice patients.

\section{Introduction}

Anaemia is common in hospice populations and associated with significant symptom burden ${ }^{1}$. Red blood cell (RBC) transfusion is frequently performed, however benefit is often short-lived and risks, including reactions and circulatory overload, are significant, leading to calls for a more restrictive approach $^{2-4}$. However, there is evidence that treating even mild to moderate anaemia may lead to symptomatic benefit and improvements in quality of life in patients with cancer ${ }^{5,6}$.

Assessing for and, if present, treating iron deficiency (ID) was a key recommendation from the recent UK comparative audit of blood transfusion practice in hospices and has the potential to treat symptoms of anaemia in certain patients without or in addition to transfusion ${ }^{4}$. ID is known to be relatively common in patients with cancer and associated with advanced disease ${ }^{7}$. Treatment of ID is recommended in oncology settings, with intravenous iron having evidence of quality of life benefit and superior efficacy and tolerability versus oral preparations ${ }^{8,9}$. Despite these considerations there is very little evidence related to ID in palliative care populations and neither investigating for, nor treating ID are routinely performed in palliative care settings ${ }^{4}$.

In this report, we aim to describe the investigation and management of ID, including the use of intravenous iron, in a UK specialist palliative care unit in order to evaluate how national guidance translates to clinical practice.

\section{Methods}

Setting

Marie Curie Hospice Liverpool provides specialist palliative care for cancer and non-cancer patients in Liverpool, North West England. It has a 20 bedded inpatient unit as well as providing outpatient services and an ambulatory blood transfusion service that accepts direct referrals for patients with advanced cancer.

\section{Design}

This is a retrospective, descriptive study of routine clinical data collected from August 2018-July 2019 following the implementation of guidance locally to investigate for ID in patients with clinically significant anaemia, in whom treatment would be appropriate. Prior to this, investigating for ID was not routine practice and to the knowledge of the clinical team there were no incidences of iron replacement being instigated locally by specialist palliative care services.

All full blood counts performed by the hospice were identified on the electronic laboratory record, with repeat sampling in the same patient excluded if performed within 6-weeks. Ferritin and iron study results were analysed if within 2 weeks of the index haemoglobin. Data on patient diagnosis, symptoms and treatments given for anaemia prior to and in response to the haemoglobin result were extracted from the electronic patient record. The presence of classic symptoms of anaemia at the time of haemoglobin check was defined as documented presence of one or more of fatigue, breathlessness or dizziness. As this was an analysis of anonymised routine clinical data generated for a locally approved audit, ethical approval was not required.

\section{Protocol for investigation of iron deficiency anaemia}

Anaemia was defined as haemoglobin $(\mathrm{Hb})$ below the age and sex-specific laboratory range and subsequently subclassified into mild $(\mathrm{Hb}>100 \mathrm{~g} / \mathrm{L})$, moderate $(\mathrm{Hb} 80-100 \mathrm{~g} / \mathrm{L}$ ) and severe $(\mathrm{Hb}<80 \mathrm{~g} / \mathrm{L})$. Iron status was assessed in patients with anaemia deemed to be clinically significant, in whom oral or intravenous management would be appropriate in the context of their overall condition and prognosis. Ferritin was checked in all patients along with transferrin saturation (TSAT) in patients with malignancy 9 . The tests were either retrospectively added to the index sample within a 48-hour period or taken at the time of haemoglobin check if anaemia was pre-existing or suspected. Blood samples were analysed according to standard practices at the local acute hospital.

\section{Protocol for interpretation of iron status and managing} iron deficiency

The protocol used for interpreting iron status is summarised in Figure 1. Absolute ID was defined as ferritin $<30 \mathrm{ng} / \mathrm{ml}$ or, in patients with cancer, ferritin $<100 \mathrm{ng} / \mathrm{ml}$ and TSAT $<20 \%^{8-10}$. Functional iron deficiency (FID) was defined as TSAT $<20 \%$ and ferritin $>30 \mathrm{ng} / \mathrm{ml}$ or $>100 \mathrm{ng} / \mathrm{ml}$ in those with cancer $^{8,11}$. Iron replacement was considered in those with absolute ID using these definitions, following national guidance to consider 


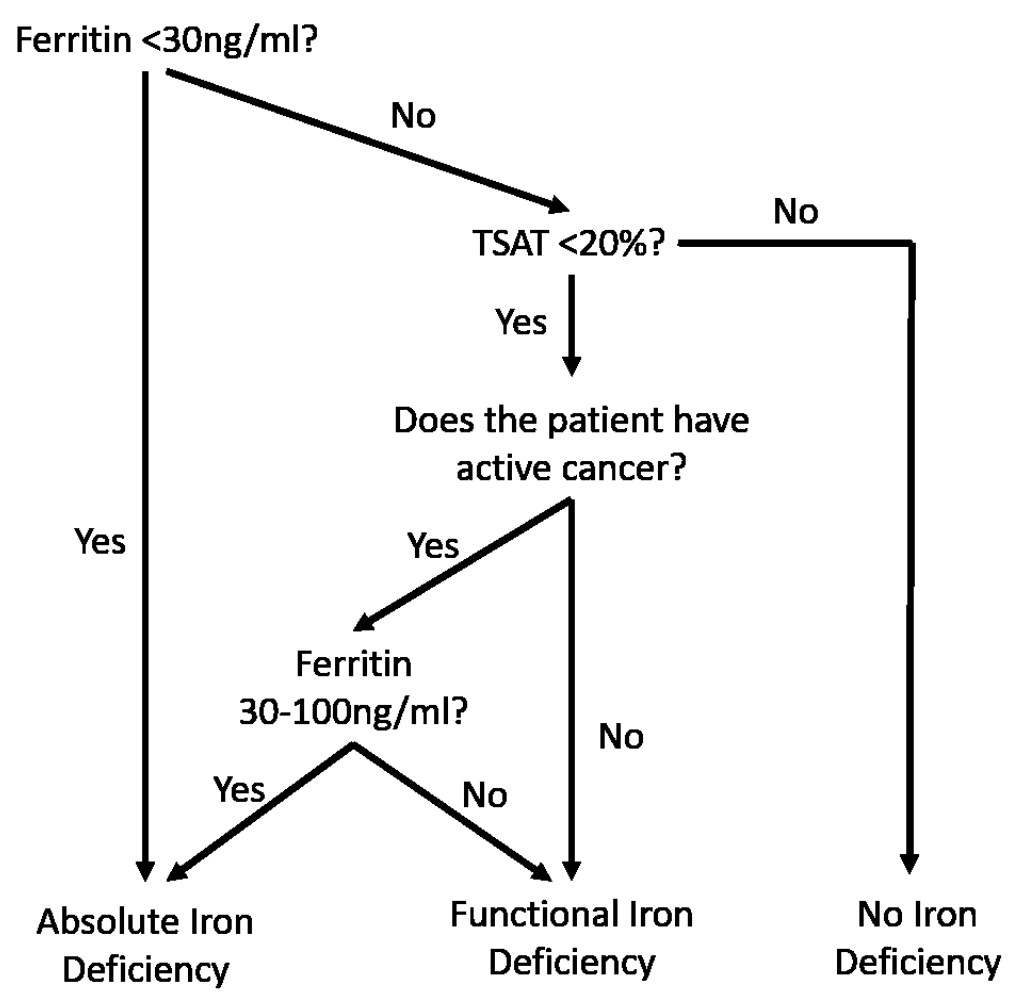

Figure 1. Algorithm for interpretation of ferritin and iron studies, based on general and oncology-specific guidance ${ }^{9,10}$.

intravenous replacement when oral iron preparations are ineffective, not tolerated or contraindicated, or when there is a clinical need to deliver iron rapidly ${ }^{10}$. If blood transfusion was deemed to also be indicated, this was given at least 24 hours prior to the iron replacement.

The protocol for delivery of intravenous iron was based on that of the partner NHS foundation trust providing pharmacy services (Liverpool Heart and Chest NHS Foundation Trust) and approved by the local medicines management and governance processes. Iron (III) isomaltoside (Monofer) was given as per the product literature with dosage calculated by weight and given as a single infusion. If the target dose exceeded the maximum single infusion dose $(>20 \mathrm{mg} / \mathrm{kg})$ then the maximum dose was given in that infusion.

\section{Data analysis}

Anonymised data was processed by Microsoft Excel and statistical analysis performed using SPSS v25 (IBM corp, USA). For comparisons between factors based on iron status, continuous data was assessed for normality and statistical tests employed as appropriate. For categorical data, chi squared test was used. Statistical significance was delineated at $\mathrm{P}<0.05$.

\section{Results}

Iron status

From $1^{\text {st }}$ August 2018 to $31^{\text {st }}$ July 2019, excluding repeats within 6-weeks, haemoglobin was checked on 294 occasions across the hospice. In total, $240(81.6 \%)$ had anaemia based on the laboratory reference range, $129(44.2 \%)$ had $\mathrm{Hb}<100 \mathrm{~g} / \mathrm{L}$ and $54(18.4 \%) \mathrm{Hb}<80 \mathrm{~g} / \mathrm{L}$. Blood transfusion was carried out in response to results in 59 cases.

Iron status was evaluated in 112 cases (57 inpatient, 55 outpatient). This represented 25/110 (22.7\%) of those with mild anaemia, $46 / 76(60.5 \%)$ of those with moderate anaemia and 41/54 (75.9\%) of those with severe anaemia. A total of 101 patients $(90.1 \%)$ had cancer, and $28(25 \%)$ a malignancy of the gastrointestinal tract. The reason for haemoglobin check were typical symptoms of anaemia in 60 (53.6\%), other symptoms in $28(25 \%)$, external referral for transfusion in $21(18.75 \%)$ and unclear in $3(2.7 \%)$.

Overall, 28 (25\%) were defined as having evidence of AID, $48(42.9 \%)$ FID and $36(32.1 \%)$ no ID. The clinical characteristics of patients with AID (potentially warranting treatment), FID and no evidence of ID are shown in Table 1. There were significant differences related to diagnosis and symptoms detected between groups, with a higher proportion of patients with classic symptoms and gastrointestinal malignancy in those with AID.

\section{Management of iron deficiency and outcomes of} intravenous iron

Intravenous iron was given on 14 occasions in 12 patients and oral iron replacement commenced in 6 patients. Of the 
Table 1. Comparison of clinical characteristics depending on iron status.

\begin{tabular}{|c|c|c|c|c|}
\hline Characteristic & $\begin{array}{l}\text { Absolute Iron } \\
\text { Deficiency }(n=28)\end{array}$ & $\begin{array}{l}\text { Functional Iron } \\
\text { Deficiency }(n=48)\end{array}$ & $\begin{array}{l}\text { No Iron } \\
\text { Deficiency }(n=36)\end{array}$ & P value \\
\hline Age (mean; SD) & $71.8(66.9-76.8)$ & $66.7(63.1-70.2)$ & $71.1(67.4-74.8)$ & $0.113^{a}$ \\
\hline Sex (\% female) & $15(53.6 \%)$ & $20(41.7 \%)$ & $12(33.3 \%)$ & $0.266^{b}$ \\
\hline $\mathrm{Hb}$ (mean; 95\% CI) & 84.1 (76.7-91.6) & $87.5(83.7-91.3)$ & 93.1 (85.4-100.9) & $0.136^{a}$ \\
\hline MCV (mean 95\% CI) & $82.2(78-86.4)$ & $82.4(80-84.7)$ & $89.7(87.3-92)$ & $<0.001^{a}$ \\
\hline $\begin{array}{l}\text { Diagnosis } \\
\text { GI tract cancer } \\
\text { Other cancer } \\
\text { Non-malignant } \\
\text { Missing }\end{array}$ & $\begin{array}{l}14(51.9 \%) \\
7(25.9 \%) \\
6(22.2 \%) \\
1\end{array}$ & $\begin{array}{l}11(22.9 \%) \\
37(77.1 \%) \\
0 \\
0\end{array}$ & $\begin{array}{l}3(8.6 \%) \\
27(77.1 \%) \\
5(14.3 \%) \\
1\end{array}$ & $<0.001^{b}$ \\
\hline $\begin{array}{l}\text { Symptoms prompting } \mathrm{Hb} \\
\text { check } \\
\text { Classic anaemiac } \\
\text { Other } \\
\text { Transfusion service referral } \\
\text { Missing }\end{array}$ & $\begin{array}{l}18(66.7 \%) \\
1(3.7 \%) \\
8(29.6 \%) \\
1\end{array}$ & $\begin{array}{l}25(53.2 \%) \\
14(29.8 \%) \\
8(17 \%) \\
0\end{array}$ & $\begin{array}{l}17(48.6 \%) \\
13(37.1 \%) \\
5(14.3 \%) \\
1\end{array}$ & $0.037^{b}$ \\
\hline 30 Day Mortality & $3(11.1 \%)$ & $17(35.4 \%)$ & $7(20 \%)$ & $0.048^{a}$ \\
\hline
\end{tabular}

remaining 10 patients with AID, 6 had clear decisions to not treat on clinical grounds documented and 4 no clear documentation. No patients treated with oral iron had subsequent intravenous iron. One did not tolerate the oral iron but no further treatment was appropriate, one had a stable haemoglobin and symptoms, and the remaining four had the oral iron stopped due to deteriorating condition, within 60 days of starting.

Twelve iron infusions were given at the hospice (in 10 patients) and two patients were referred for treatment elsewhere, one due to issues with intravenous access, the other due to patient preference. Of those delivered at the hospice, 4 $(33.3 \%)$ were to inpatients, the remainder day cases. The clinical characteristics of the patients treated at the hospice are displayed in Table 2. There were no major adverse effects from iron infusion. One patient had minor extravasation of iron causing discolouration. Four patients (33.3\%) received RBC transfusion for the same episode of anaemia. Three patients (25\%) had subsequent RBC transfusion, between one and three months later. These had all had received RBC transfusion prior to the iron infusion and two were already classed as transfusion dependent, both showed an apparent decrease in transfusion dependency.

Of 12 patients receiving intravenous iron, 7 (58\%) had a documented symptom benefit at four weeks, (including 6/8 of those who were given intravenous iron alone). Of the remaining five, one died within a week of the infusion, two did not have clinical follow up at the hospice and two did not have documented effect. Changes in haemoglobin for those with available results at $2-4,6-8$ and $10-14$ weeks are shown in Table 3 and indicate a sustained mean increase. Those receiving subsequent transfusion were not included past the point of transfusion. Overall, $11 / 12$ survived to 30 days, 11/12 to 60 days and $7 / 12$ to 90 days.

\section{Discussion}

\section{Main findings}

This descriptive study showed iron deficiency to be common among patients with clinically significant anaemia in this UK hospice population. ID appeared to be associated with gastrointestinal malignancy, which is consistent with reports in oncology settings? ${ }^{7}$. Rates were also higher amongst those in whom the original haemoglobin check was prompted by classic symptoms of anaemia or referral for transfusion compared with others, in whom anaemia may have been an incidental finding. The 30-day mortality appeared highest amongst those with FID, which is in keeping with the association of ferritin with inflammation and evidence of elevated ferritin being a poor prognostic indicator in several cancers ${ }^{12,13}$.

Importantly, the majority of patients with iron deficiency identified did receive specific treatment, including the novel use of intravenous iron in the hospice setting in 12 patients. This was well tolerated with no major adverse events and was managed safely both on the hospice ward and in an ambulatory setting. As this is a descriptive study, conclusions 


\begin{tabular}{|c|c|c|}
\hline Demographics $(n=10)$ & $\begin{array}{l}\text { Female sex } \\
\text { Age (median, range) } \\
\text { Cancer diagnosis } \\
\text { Gastrointestinal malignancy }\end{array}$ & $\begin{array}{l}6(60 \%) \\
71(35-88) \\
8(80 \%) \\
6(60 \%)\end{array}$ \\
\hline $\begin{array}{l}\text { Laboratory values } \\
\text { (median, range) }\end{array}$ & $\begin{array}{l}\text { Haemoglobin }(\mathrm{g} / \mathrm{dL}) \\
\mathrm{MCV}(\mathrm{fL}) \\
\text { Ferritin (ug/L) }\end{array}$ & $\begin{array}{l}83.5(55-114) \\
77.2(68-98.5) \\
22(5-80)\end{array}$ \\
\hline Red blood cell transfusion & $\begin{array}{l}\text { Previously (within } 3 \text { months) } \\
\text { For same episode }\end{array}$ & $\begin{array}{l}6(50 \%) \\
4(33 \%)\end{array}$ \\
\hline Symptoms & $\begin{array}{l}\text { Fatigue } \\
\text { Breathlessness } \\
\text { Bleeding }\end{array}$ & $\begin{array}{l}12(100 \%) \\
4(33 \%) \\
2(17 \%)\end{array}$ \\
\hline Oral iron & $\begin{array}{l}\text { Taking, ineffective } \\
\text { Not tolerated } \\
\text { Contraindicated }\end{array}$ & $\begin{array}{l}6(50 \%) \\
3(25 \%) \\
3(25 \%)\end{array}$ \\
\hline
\end{tabular}

\begin{tabular}{|c|c|c|c|}
\hline Follow up period & 2-4 weeks & 6-8 weeks & $10-12$ weeks \\
\hline $\begin{array}{l}\text { Number with available results } \\
\text { Of all patients } \\
\text { Simultaneous transfusion excluded }\end{array}$ & $\begin{array}{l}10 \\
7\end{array}$ & $\begin{array}{l}8 \\
6\end{array}$ & $\begin{array}{l}6 \\
6\end{array}$ \\
\hline $\begin{array}{l}\text { Missing data explanation } \\
\text { Patient died } \\
\text { Follow up elsewhere } \\
\text { No available result in time-frame } \\
\text { Results excluded due to transfusion }\end{array}$ & $\begin{array}{l}1 \\
0 \\
1 \\
0\end{array}$ & $\begin{array}{l}1 \\
2 \\
1 \\
0\end{array}$ & $\begin{array}{l}4^{a} \\
1 \\
0 \\
1^{b}\end{array}$ \\
\hline $\begin{array}{l}\text { Haemoglobin ( } \mathrm{g} / \mathrm{L} \text { ) change from } \\
\text { baseline (mean; } 95 \% \mathrm{CI} \text { ) } \\
\text { All patients } \\
\text { Simultaneous transfusions excluded }\end{array}$ & $\begin{array}{l}15.1(6-24.2) \\
15.1(2.6-27.7)\end{array}$ & $\begin{array}{l}16.8(3.9-29.6) \\
18.7(1-36.3)\end{array}$ & $\begin{array}{l}19.7(10.6-28.8) \\
19.7(10.6-28.8)\end{array}$ \\
\hline $\begin{array}{l}\text { Proportion of patients with increase in } \\
\text { haemoglobin (\%) } \\
\text { All patients } \\
\text { Simultaneous transfusion excluded }\end{array}$ & $\begin{array}{l}9(90 \%) \\
6(85.7 \%)\end{array}$ & $\begin{array}{l}7(87.5 \%) \\
5(83.3 \%)\end{array}$ & $\begin{array}{l}6(100 \%) \\
6(100 \%)\end{array}$ \\
\hline
\end{tabular}

Results from haemoglobin checks performed in usual clinical practice in the relevant time-frames. ${ }^{\circ}$ Five patients died within 12 weeks, however one also had follow up haemoglobin in 10-12 week timeframe. ${ }^{b} T$ hree patients had subsequent transfusion, two of these also died so missing data classified under that explanation.

cannot be drawn regarding the efficacy of this intervention, however, apparent improvements in haemoglobin and symptoms were encouraging.
Unique contribution and strengths

This project is the first to report the implementation of investigating for ID amongst patients with clinically significant 
anaemia into routine clinical practice in a hospice setting. The data generated is from a real-world setting meaning it is likely to be generalisable to similar settings. It is also the largest description of the iron status of patients in this setting with clinically significant anaemia and not exclusively receiving blood transfusion.

This is the first report to our knowledge of the use of intravenous iron in a hospice setting. This intervention was used in keeping with recommendations for treating ID and within the established indication of oral iron being ineffective, not tolerated or contraindicated ${ }^{10}$. Intravenous iron is widely used in non-malignant conditions including renal and heart failure and evidence in cancer patients of superior efficacy, tolerability and speed of effect compared with oral iron supports it being considered for first-line use of intravenous iron in appropriate palliative care patients ${ }^{14-16}$.

\section{Comparison with previous work}

Our findings confirm that anaemia in hospices is a significant problem. There is very little published data on management from either a technical or practical perspective. A recently published UK-wide audit described blood transfusion practice in hospices, which our report extends to patients with anaemia not receiving a transfusion ${ }^{4}$. This audit suggested ID to be present in a significant proportion of patients, however, smaller, older case series in palliative care settings have shown conflicting reports of prevalence ${ }^{1,4,17}$. ID may have been more common in our report as investigations were targeted at those with clinically significant anaemia.

Importantly, diagnosis of iron deficiency is not straight forward in palliative care settings and varying definitions have been used $^{4,18}$. Ferritin levels are elevated in systemic inflammation, leading to a higher cut off being recommended for diagnosis of AID in cancer patients if TSAT is low ${ }^{8}$ FID is a state in which there is insufficient iron available for erythropoiesis despite adequate total body iron stores and is important in the anaemia of malignancy ${ }^{11,16}$. Percentage hypochromic red blood cells has been proposed as an indicator of FID in palliative care patients but is not available widely, or locally ${ }^{18}$. We used the combination of ferritin and TSAT, with specific interpretation in those with cancer to identify "absolute" and "functional" iron deficiency based on existing evidence, recommendations from oncology populations and local availability $^{8-11}$. Our results support evidence that FID is very common in palliative care patients, however evidence to inform management of FID, particularly the role of intravenous iron, is significantly lacking ${ }^{18}$.

\section{Implications to policy and/or practice}

Our results suggest that guidance to investigate for and treat ID can be implemented into clinical practice in hospices. This allows treatment of anaemic patients with ID either in place of or addition to blood transfusion, or where transfusion would not be indicated but symptoms are still experienced. This is likely to be relevant across palliative care settings, even if local procedures and guidance varies.
Considering the appropriateness of investigations and treatments potentially close to the end of life is important. The facility to retrospectively add tests to existing blood samples helped ensure that patients did not undergo additional venepuncture. The data from patients receiving intravenous iron was encouraging and support the use of this intervention within its established indication in appropriately selected patients with AID in hospices. Although the majority of patients who received intravenous iron survived beyond 90 days, one died within 30 days. It is vital to consider overall prognosis, function and anticipated time to effectiveness when considering any form of management for anaemia. Oral iron supplementation is often associated with gastrointestinal side effects and decisions on prescription and continuation of this intervention close to the end of life should be individualised and the result of shared decision-making with the patient and those important to them. Utilisation of single doses of intravenous iron as a "first line option" may have the potential of reducing this burden and potentially facilitate deprescribing.

Investigating for and treating ID is associated with cost, however this may be offset by potential reduction of blood transfusion, unplanned hospital admission or other healthcare utilisation costs due to anaemia. Our ability to deliver this intervention via an established ambulatory transfusion service allowed it to be given to outpatients and the process was more straightforward than for blood transfusion as cross-matching is not required. Further research is needed to further address the cost effectiveness of this approach, effect on quality of life, and whether there is any role for intravenous iron in anaemia more widely, particularly FID.

\section{Limitations}

This study is limited by its retrospective and descriptive nature. Investigating for ID was reliant of clinical decision making, therefore the prevalence in the wider hospice population cannot be inferred. Symptoms recorded were limited to the indication for the haemoglobin check and data was missing on ethnicity, functional status, co-morbidities and rationale for decisions over testing and treatment. The analysis of the patients receiving intravenous iron is also limited by the use of routine data which meant that there was no comparison group, follow up was not consistent in timing or assessment of symptoms. Furthermore, the number of patients receiving intravenous iron were small and we are unable to assess the effect of the overall approach on transfusion data at the hospice as service developments mean data would not be comparable over time.

\section{Conclusions}

Investigating for iron deficiency and treating if present can be considered for appropriate hospice patients with clinically significant anaemia, particularly with underlying gastrointestinal malignancy and classic anaemia symptoms. In addition, we describe the safe use of intravenous iron in a hospice setting for the first time. Further research should focus on the optimum use of this intervention and detailed economic evaluation of this approach. 


\section{Ethical approval}

This analysis used routine clinical data in fully anonymised form that was generated from an audit of management of anaemia prompted by published recommendations from the national comparative audit of red cell transfusion practice in hospices ${ }^{4}$. The audit and subsequent analysis were approved by the Marie Curie Hospice Liverpool audit governance process and additional ethical approval was not required.

\section{Data availability}

Underlying data

Figshare: Investigation and management of iron deficiency anaemia in a specialist palliative care setting and the role of intravenous iron: a descriptive analysis of hospice data, https://doi.org/10.6084/m9.figshare.13577882.v1 ${ }^{19}$

Data are available under the terms of the Creative Commons Zero "No rights reserved" data waiver (CC0 1.0 Public domain dedication).

\section{Acknowledgements}

Thank you to all staff at Marie Curie Hospice Liverpool who engaged with the project to implement investigation of iron status into clinical practice that led to this work. The roles of all of the authors are supported by Marie Curie.
1. Dunn A, Carter J, Carter H: Anemia at the End of Life: Prevalence, Significance, and Causes in Patients Receiving Palliative Care. J Pain Symp Manag. 2003; 26(6): 1132-39. Munag. 2003; 26(6): 1132-39.
PubMed Abstract | Publisher Full Text

2. Preston NJ, Hurlow A, Brine J, et al.: Blood transfusions for anaemia in patients with advanced cancer. Cochrane Database Syst Rev. 2012; 2012(2): CD009007.

PubMed Abstract | Publisher Full Text | Free Full Text

3. Chin-Yee N, Taylor J, Rourke K, et al.: Red blood cell transfusion in adult palliative care: a systematic review. Transfusion. 2018; 58(1): 233-241. PubMed Abstract | Publisher Full Text

4. Neoh K, Gray R, Grant-Casey J, et al:: National comparative audit of red blood cell transfusion practice in hospices: Recommendations for palliative care practice. Palliat Med. 2019; 33(1): 102-108.

PubMed Abstract | Publisher Full Text | Free Full Text

5. Lind $M$, Vernon C, Cruickshank D, et al.: The level of haemoglobin in anaemic cancer patients correlates positively with quality of life. Br J Cancer. 2002; 86(8): 1243-1249.

PubMed Abstract | Publisher Full Text | Free Full Text

6. Straus DJ, Testa MA, Sarokhan BJ, et al:: Quality-of-Life and Health Benefits of Early Treatment of Mild Anemia: a randomized trial of epoetin alfa in patients receiving chemotherapy for hematologic malignancies. Cancer. 2006; 107(8): 1909-1917.

PubMed Abstract | Publisher Full Text

7. Ludwig $\mathrm{H}$, Müldür $\mathrm{E}$, Endler $\mathrm{G}$, et al:: Prevalence of iron deficiency across different tumors and its association with poor performance status, disease status and anemia. Ann Oncol. 2013; 24(7): 1886-1892. PubMed Abstract | Publisher Full Text | Free Full Text

8. Ludwig $\mathrm{H}$, Evstatiev R, Kornek $\mathrm{G}$, et al.: Iron metabolism and iron supplementation in cancer patients. Wien Klin Wochenschr. 2015; 127(23-24): 907-919.

PubMed Abstract | Publisher Full Text | Free Full Text

9. Aapro $M$, Beguin $Y$, Bokemeyer $C$, et al:: Management of anaemia and iron deficiency in patients with cancer: ESMO Clinical Practice Guidelines. Ann Oncol. 2018; 29(Suppl 4): iv96-iv110.

PubMed Abstract | Publisher Full Text

10. Goddard AF, James MW, McIntyre AS, et al.: Guidelines for the management of iron deficiency anaemia. Gut. 2011; 60(10): 1309-1316.

PubMed Abstract | Publisher Full Text
11. Thomas DW, Hinchcliffe RF, Briggs C, et al.: Guideline for the laboratory diagnosis of functional iron deficiency. Br J Haematol. 2013; 161(5): 639-648. PubMed Abstract | Publisher Full Text

12. Kalousová $\mathrm{M}, \mathrm{Krechler} \mathrm{T}$, Jáchymová $\mathrm{M}$, et al:: Ferritin as an Independent Mortality Predictor in Patients With Pancreas Cancer. Results of a Pilot Study. Tumour Biol. 2012; 33(5): 1695-700. PubMed Abstract | Publisher Full Text

13. Lee $\mathrm{S}$, Jeon H, Shim B: Prognostic Value of Ferritin-to-Hemoglobin Ratio in Patients with Advanced Non-Small-Cell Lung Cancer. J Cancer. 2019; 10(7): 1717-1725.

PubMed Abstract | Publisher Full Text | Free Full Text

14. Aapro M, Österborg A, Gascón P, et al.: Prevalence and management of cancer-related anaemia, iron deficiency and the specific role of i.v. iron Ann Oncol. 2012; 23(8): 1954-1962. PubMed Abstract | Publisher Full Text

15. Mikail A, Brown C, Williams JA, et al:: Renal association clinical practice guideline on Anaemia of Chronic Kidney Disease. BMC Nephrol. 2017; 18(1): 345. PubMed Abstract | Publisher Full Text | Free Full Text

16. Ponikowski P, Voors AA, Anker SD, et al.: 2016 ESC Guidelines for the diagnosis and treatment of acute and chronic heart failure: The Task Force for the diagnosis and treatment of acute and chronic heart failure of the European Society of Cardiology (ESC)Developed with the special contribution of the Heart Failure Association (HFA) of the ESC. Eur Heart J. 2016; 37(27): 2129-2200.

PubMed Abstract | Publisher Full Text

17. Robertson KA, Hutchison SMW: Assessment of iron status and the role for iron-replacement therapy in anaemic cancer patients under the care of a specialist palliative care unit. Palliat Med. 2009; 23(5): 406-409. PubMed Abstract | Publisher Full Text

18. Neoh K, Stanworth S, Pasricha SR, et al.: Estimating prevalence of functional iron deficiency anaemia in advanced cancer. Support Care Cancer. 2017; 25(4): 1209-1214. PubMed Abstract | Publisher Full Text

19. Steele $T$, Bonwick $H$, Chapman L, et al.: Investigation and management of iron deficiency anaemia in a specialist palliative care setting and the role of intravenous iron: a descriptive analysis of hospice data. figshare. 2021. http://www.doi.org/10.6084/m9.figshare.13577882.v1 


\section{Open Peer Review}

\section{Current Peer Review Status:}

Version 1

Reviewer Report 22 February 2021

https://doi.org/10.21956/amrcopenres.14034.r26625

(C) 2021 Dickson E. This is an open access peer review report distributed under the terms of the Creative Commons Attribution License, which permits unrestricted use, distribution, and reproduction in any medium, provided the original work is properly cited.

\section{Edward A. Dickson}

National Institute for Health Research Biomedical Research Unit, Gastrointestinal and Liver Diseases, Nottingham University Hospitals NHS Trust, Nottingham, UK

Thank you for the opportunity to review this descriptive case series of anaemic patients being managed in a palliative care setting and the use of intravenous iron therapy in this group. Steele et al. make an important contribution to the literature in an area with limited evidence to date.

The abstract describes the background and methods used by the authors well. However, the data in the results could be clearer. The percentages presented seem to differ to the results of the main manuscript and need to be checked. It could also be clearer that these percentages for iron studies relate to the total number of patients with confirmed anaemia. The authors state a "significant increase in overall mean haemoglobin were observed". Does this mean clinically significant, or statistically significant?

The plain English summary provides a good overview of the study but may benefit from a simplified explanation of anaemia for the lay person.

The introduction is clearly written and highlights the issue being addressed well. References to the literature provide the rationale for the study and serve to summarise the key limitations of existing treatment options i.e. blood transfusion. The authors also describe the benefits of intravenous iron in other settings.

The authors have described their methodology well with a definition of iron deficiency and a description of their treatment pathway. It would be useful to understand how clinically significant anaemia was defined - was this based on patient reported symptoms? Or clinician perception? The authors refer to the study as a locally approved audit and therefore it is important to state the standards against which they were auditing. They also describe implementation of local guidance before the study was conducted. It would be useful to know details of this for other centres to potentially employ. 
Division of anaemia into mild/moderate/severe is in keeping with WHO standards and would be useful to guide response to therapy. Particularly, as the authors acknowledge in the background, there may be benefits in treating even mild anaemia. The figure explaining how iron studies were interpreted is clear and well defined. The authors describe adding iron studies retrospectively to the full blood count. Was this performed by the clinical team at the time? Or was this prompted by the study team?

Although this is a retrospective study the description of the data analysis would benefit from more detail on the outcome measures the authors planned to use. A description of the audit standards would also be welcome as mentioned earlier.

The results section offers a good indication as to the prevalence of anaemia at this centre. It would be useful to see details on the 59 cases who were transfused. Were these patients more profoundly anaemic and deemed not appropriate for iron, or did they not receive iron despite meeting the local guidance for iron replacement therapy? Also, were any patient receiving myelosuppressive chemotherapy? This would be helpful to know given its confounding effect on haemoglobin. It appears all patients who received intravenous iron had absolute iron deficiency. Was there a local decision not treat functional iron deficiency with IV iron or was this coincidence? There is evidence to support its benefits in FID in other pathologies.

The outcomes of intravenous iron therapy offer some important insights as to the feasibility of this treatment within the palliative care population. Did the two patients who received two doses require a split dose (due to the $20 \mathrm{mg} / \mathrm{kg} /$ week limit) or were they given a further iron infusion at a later date as is sometimes used in other pathologies? Can the authors comment on why three patients had a subsequent RBC infusion after their iron. Was this due to a fall in haemoglobin, or a lack of benefit?

Symptom relief is an important outcome measure for this patient group. Whilst I appreciate the authors are reliant on retrospective data it would be useful to know further details on which symptoms had improved if this is available.

The data presented in Table 3 is helpfully divided by those who did and did not receive simultaneous blood transfusion. It is interesting to see that haemoglobin was higher in the nontransfused group at 6-8 weeks. Can the authors comment on this?

The discussion is well structured and covers a number of important points. The limitations of the study are well acknowledged with good reference to previous smaller case series. The authors have demonstrated that their model is feasible and may offer patients an alternative option to repeated transfusion, particularly within an ambulatory setting. Steele et al. should be commended on publishing this case series in an area lacking high quality evidence. I would encourage the authors and other palliative care groups to publish future prospective data offering a robust evaluation of the efficacy of intravenous iron against a comparator group..

\section{Is the work clearly and accurately presented and does it cite the current literature? Yes}

Is the study design appropriate and is the work technically sound? 
Are sufficient details of methods and analysis provided to allow replication by others? Partly

If applicable, is the statistical analysis and its interpretation appropriate? Yes

Are all the source data underlying the results available to ensure full reproducibility? Yes

Are the conclusions drawn adequately supported by the results? Yes

Competing Interests: No competing interests were disclosed.

Reviewer Expertise: Clinical research fellow with an interest in iron deficiency anaemia and intravenous iron therapy in advanced cancer and palliative care.

I confirm that I have read this submission and believe that I have an appropriate level of expertise to confirm that it is of an acceptable scientific standard, however I have significant reservations, as outlined above.

Author Response 25 Feb 2021

Thomas Steele, Marie Curie Hospice, Liverpool, UK

Thank you for reviewing our article, your positive feedback and constructive criticisms. We are glad to share our experiences with this approach to managing anaemia in a hospice setting, especially with there being so little evidence relating to non-transfusion therapies for anaemia in palliative care populations. We agree with your analysis of the limitations of our work and share your hope it gives encouragement towards trials of intravenous iron in this setting. As a result of your feedback we have made amendments to the paper and feel it improved as a result. I have responded to your comments point by point below.

Thank you for the opportunity to review this descriptive case series of anaemic patients being managed in a palliative care setting and the use of intravenous iron therapy in this group. Steele et al. make an important contribution to the literature in an area with limited evidence to date.

The abstract describes the background and methods used by the authors well. However, the data in the results could be clearer. The percentages presented seem to differ to the results of the main manuscript and need to be checked. It could also be clearer that these percentages for iron studies relate to the total number of patients with confirmed anaemia. The authors state a "significant increase in overall mean haemoglobin were observed". Does this mean clinically significant, or statistically significant?

Thank you for noting these issues in the results section of the abstract. A typo has been 
corrected relating to the proportion of those with moderate anaemia and we have clarified significant to refer to statistically (although this level of increase would generally also be felt to be clinically relevant).

The plain English summary provides a good overview of the study but may benefit from a simplified explanation of anaemia for the lay person.

Thank you for this feedback we have added this.

The introduction is clearly written and highlights the issue being addressed well.

References to the literature provide the rationale for the study and serve to summarise the key limitations of existing treatment options i.e. blood transfusion. The authors also describe the benefits of intravenous iron in other settings.

The authors have described their methodology well with a definition of iron deficiency and a description of their treatment pathway. It would be useful to understand how clinically significant anaemia was defined - was this based on patient reported symptoms? Or clinician perception? The authors refer to the study as a locally approved audit and therefore it is important to state the standards against which they were auditing. They also describe implementation of local guidance before the study was conducted. It would be useful to know details of this for other centres to potentially employ.

We have amended our methods section significantly to clarify these points. Most significantly, the aim of the audit which generated the data is now described and the prompt for this, based on published national recommendations for practice, explained. A main component of the guidance was the protocols for investigation and management described in the methods section, this is now more clearly stated in the text.

Division of anaemia into mild/moderate/severe is in keeping with WHO standards and would be useful to guide response to therapy. Particularly, as the authors acknowledge in the background, there may be benefits in treating even mild anaemia. The figure explaining how iron studies were interpreted is clear and well defined. The authors describe adding iron studies retrospectively to the full blood count. Was this performed by the clinical team at the time? Or was this prompted by the study team?

This was performed by the clinical team at the time and was all routine data. This is now clarified in the text. Unfortunately, it is not possible to tell how often there were "add ons" but we felt it important to emphasise the approach does not necessarily lead to more venepuncture for patients.

Although this is a retrospective study the description of the data analysis would benefit from more detail on the outcome measures the authors planned to use. A description of the audit standards would also be welcome as mentioned earlier.

We have now added to the data analysis paragraph the planned primary and additional outcome measures, with context given by the description of the aim of the audit and specific standard relating to consideration of treatment of iron deficiency. We hope this gives a clearer picture to the reader of the data generated and how retrospective analysis was planned.

The results section offers a good indication as to the prevalence of anaemia at this centre. 
It would be useful to see details on the 59 cases who were transfused. Were these patients more profoundly anaemic and deemed not appropriate for iron, or did they not receive iron despite meeting the local guidance for iron replacement therapy?

The decision-making process for considering iron was the same whether or not RBC transfusion was given- ie based on iron status (AID) rather what their heamoglobin was. In those with AID but transfusion potentially also appropriate the decision which to prioritise was based on clinical grounds, often in quite complex cases with multiple considerations (prognosis, severity of symptoms, suspected other aetiologies) which is unfortunately difficult to capture. We have added more details of the iron status specifically of those who were transfused which hopefully will help with context.

Also, were any patient receiving myelosuppressive chemotherapy? This would be helpful to know given its confounding effect on haemoglobin. It appears all patients who received intravenous iron had absolute iron deficiency. Was there a local decision not treat functional iron deficiency with IV iron or was this coincidence? There is evidence to support its benefits in FID in other pathologies.

We only considered iron replacement in those meeting the definition of absolute iron deficiency. Although there is evidence supporting treatment of FID in certain conditions we lack evidence this is applicable across our general population, therefore treatment followed general national guidance. Note that the definition of AID used in cancer patients was adapted and not based on low ferritin alone to account for the presence and effect of inflammation in this situation. Hopefully our results showing implementation of IV iron in those with this definition of AID demonstrate that specifically investigating IV iron in those with FID in palliative care settings is needed.

The outcomes of intravenous iron therapy offer some important insights as to the feasibility of this treatment within the palliative care population. Did the two patients who received two doses require a split dose (due to the $20 \mathrm{mg} / \mathrm{kg} / \mathrm{week}$ limit) or were they given a further iron infusion at a later date as is sometimes used in other pathologies? Can the authors comment on why three patients had a subsequent RBC infusion after their iron. Was this due to a fall in haemoglobin, or a lack of benefit?

We have now specified when more than one dose was given these were separate episodes. If requiring over $20 \mathrm{mg} / \mathrm{kg}$ the policy was to give maximum single dose and then review clinically as this was felt to be the best balance of benefit vs burden in our population. With regards to subsequent transfusion this is challenging to answer and it is not feasible to go deeply into individual level data in the main manuscript, however two of these patients were transfusion dependent already and in one the subsequent transfusion was at higher $\mathrm{Hb}$ threshold than baseline. As with the rest of this report we are limited by our reliance on clinician documentation. The raw data can give some further insight that might help plan further work.

Symptom relief is an important outcome measure for this patient group. Whilst I appreciate the authors are reliant on retrospective data it would be useful to know further details on which symptoms had improved if this is available.

Agreed, unfortunately, we were unable to answer this in a meaningful way with the documentation available and hopefully this can be analysed further in future work. 
The data presented in Table 3 is helpfully divided by those who did and did not receive simultaneous blood transfusion. It is interesting to see that haemoglobin was higher in the non-transfused group at 6-8 weeks. Can the authors comment on this?

We wanted to ensure we presented the results with simultaneous transfusion excluded to ensure effects seen were not just the transfusion in those that received it. As stated, the results are interesting. We are reluctant to comment in more detail within the paper given this analysis was not the aim of the paper, and the sample size becomes very small. Speculating on possible reasons for those individuals, the effect of transfusion in this population is often very transient. It is also possible that those who also required transfusion may have had more multifactorial anaemia and therefore less response to the intravenous iron.

The discussion is well structured and covers a number of important points. The limitations of the study are well acknowledged with good reference to previous smaller case series. The authors have demonstrated that their model is feasible and may offer patients an alternative option to repeated transfusion, particularly within an ambulatory setting. Steele et al. should be commended on publishing this case series in an area lacking high quality evidence. I would encourage the authors and other palliative care groups to publish future prospective data offering a robust evaluation of the efficacy of intravenous iron against a comparator group.

Many thanks again for your time spent reviewing our work.

Competing Interests: None

Reviewer Report 18 February 2021

https://doi.org/10.21956/amrcopenres.14034.r26623

(C) 2021 Urban K. This is an open access peer review report distributed under the terms of the Creative Commons Attribution License, which permits unrestricted use, distribution, and reproduction in any medium, provided the original work is properly cited.

\section{Katalin Urban}

Palliative Care Department, Lismore Base Hospital, Lismore, NSW, Australia

Thank you for this contribution to the literature in managing iron deficiency in the inpatient palliative care setting, and how national guidelines translate to practice in this situation.

There is a typo in the abstract, it is reported that 112 cases had iron status evaluated, representing $25 / 110$ of those with mild anaemia, 26/76 with moderate and 41/54 with severe anaemia, however in the results section it is $46 / 76$ for moderate anaemia (not 26 ) - these numbers add up to 112 whereas those in the abstract do not thus I assume are incorrect, please rectify.

The aim and setting are clearly described and the methods section is well written and easy to 
follow.

Retrospective data collection often does lead to bias and is dependent on documentation quality in the Design section, it is stated that the documentation of the presence of classic symptoms of anaemia were sought, however this is very heavily reliant on documentation and an absence of documentation does not necessarily mean they were not present.

Prospective collection of data would have added a great deal to the validity of this study, with identification of data to be collected in advance - the authors acknowledge this in limitations.

With regards to the protocol for investigating iron deficiency anaemia, it would help reproducibility if the authors could clarify how it was decided if oral/iv management would be appropriate - especially as in results it states that 6 patients with AID had clear decisions not to treat on clinical grounds.

Figure 1 is a great visual representation of the diagnostic process. All 3 tables are clear and easy to understand.

Results - A great overview of the change in practice is provided. Whilst the focus was not outcomes, it is reported that $58 \%$ had a documented symptom benefit, however there is no further information on which symptoms and what level of improvement. This information, as well as quality of life measures, would add value. I realise that the aim of this study was not to look at outcomes, and as the authors point out further research is needed to clarify this.

I am curious why iron levels were not reported (as they are documented in the raw data).

It is interesting to note, when the raw data is reviewed, that only 2 of the 12 patients treated with iv iron had an MCV over 80 - this is not commented on, though it is discussed that lower MCV does correlate with iron deficiency as expected. I would be interested to hear what the authors make of this. Is this a coincidence?

A great start to showing that implementation of guidelines is possible and that iron infusions seem doable and safe $n$ the hospice setting. In terms of future directions, a prospective study evaluating the overall benefit to patients would be a great next step.

\section{Is the work clearly and accurately presented and does it cite the current literature?} Yes

Is the study design appropriate and is the work technically sound? Yes

Are sufficient details of methods and analysis provided to allow replication by others? Yes

If applicable, is the statistical analysis and its interpretation appropriate? Yes

Are all the source data underlying the results available to ensure full reproducibility? 
Yes

Are the conclusions drawn adequately supported by the results?

Yes

Competing Interests: No competing interests were disclosed.

Reviewer Expertise: palliative care, fatigue, communication, sleep, renal supportive care

I confirm that I have read this submission and believe that I have an appropriate level of expertise to confirm that it is of an acceptable scientific standard.

Author Response 25 Feb 2021

Thomas Steele, Marie Curie Hospice, Liverpool, UK

Thank you for reviewing our article, your positive feedback and constructive criticisms. We completely agree with your analysis of the limitations of the work, particularly its retrospective design and hope it can be a step towards a prospective study with robust analysis of the effect of iron replacement on symptom burden in future. We have made some amendments based on your comments, which I have explained point by point, along with specific responses to your comments, below.

Thank you for this contribution to the literature in managing iron deficiency in the inpatient palliative care setting, and how national guidelines translate to practice in this situation.

There is a typo in the abstract, it is reported that 112 cases had iron status evaluated, representing 25/110 of those with mild anaemia, 26/76 with moderate and 41/54 with severe anaemia, however in the results section it is 46/76 for moderate anaemia (not 26) - these numbers add up to 112 whereas those in the abstract do not thus I assume are incorrect, please rectify.

Thank you for pointing this out, we have amended accordingly.

The aim and setting are clearly described and the methods section is well written and easy to follow.

Retrospective data collection often does lead to bias and is dependent on documentation quality in the Design section, it is stated that the documentation of the presence of classic symptoms of anaemia were sought, however this is very heavily reliant on documentation and an absence of documentation does not necessarily mean they were not present.

Agreed. To make this clearer to the reader we have specified where exactly these were documented (methods section, design) and highlighted reliance on documentation as a limitation.

Prospective collection of data would have added a great deal to the validity of this study, with identification of data to be collected in advance - the authors acknowledge this in limitations. Hopefully this report will support funding and approvals for a prospective trial. 
With regards to the protocol for investigating iron deficiency anaemia, it would help reproducibility if the authors could clarify how it was decided if oral/iv management would be appropriate - especially as in results it states that 6 patients with AID had clear decisions not to treat on clinical grounds.

Thanks for pointing out the need for more clarity here, we have significantly amended the paragraph "protocol for interpretation of iron status and managing iron deficiency" to explain the decision-making process more clearly. Table 2 includes the reason why intravenous iron was indicated (final row).

Figure 1 is a great visual representation of the diagnostic process. All 3 tables are clear and easy to understand.

Results - A great overview of the change in practice is provided. Whilst the focus was not outcomes, it is reported that 58\% had a documented symptom benefit, however there is no further information on which symptoms and what level of improvement. This information, as well as quality of life measures, would add value. I realise that the aim of this study was not to look at outcomes, and as the authors point out further research is needed to clarify this.

Agreed, this was limited by documentation, now more clearly highlighted as a limitation.

I am curious why iron levels were not reported (as they are documented in the raw data).

Iron levels are reported as part of "iron studies" in our locality but aren't felt to be a reliable indicator of iron status in isolation and ferritin primarily and, in the context of inflammation, transferrin saturation recommended to inform decision making. Ref 11 gives some more detail about the complex area of functional iron deficiency relevant here. In order to make as relevant as possible to clinical practice we therefore reported ferritin/TSAT in the main manuscript but were keen to ensure all parts of iron studies were included in raw data in case of interest to groups in the future.

It is interesting to note, when the raw data is reviewed, that only 2 of the 12 patients treated with iv iron had an MCV over 80 - this is not commented on, though it is discussed that lower MCV does correlate with iron deficiency as expected. I would be interested to hear what the authors make of this. Is this a coincidence?

Thanks for this, it is an interesting observation, especially as in the AID group as a whole the mean MCV is over 80. It is possible that lower MCV could have influenced clinician judgement- in particular the perceived likelihood of iron replacement being helpful. It would be interesting to see this being reported in further studies. Or it could be an observation that would disappear with a larger sample of IV iron patients. A particular area where we need more evidence is functional iron deficiency in which a low MCV wouldn't typically be seen.

A great start to showing that implementation of guidelines is possible and that iron infusions seem doable and safe $n$ the hospice setting. In terms of future directions, a prospective study evaluating the overall benefit to patients would be a great next step.

Thanks again for the time spent reviewing our work. 
Competing Interests: None 